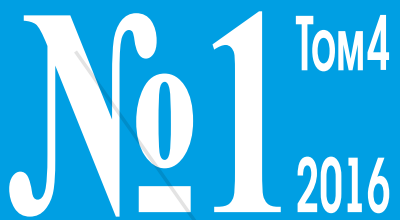

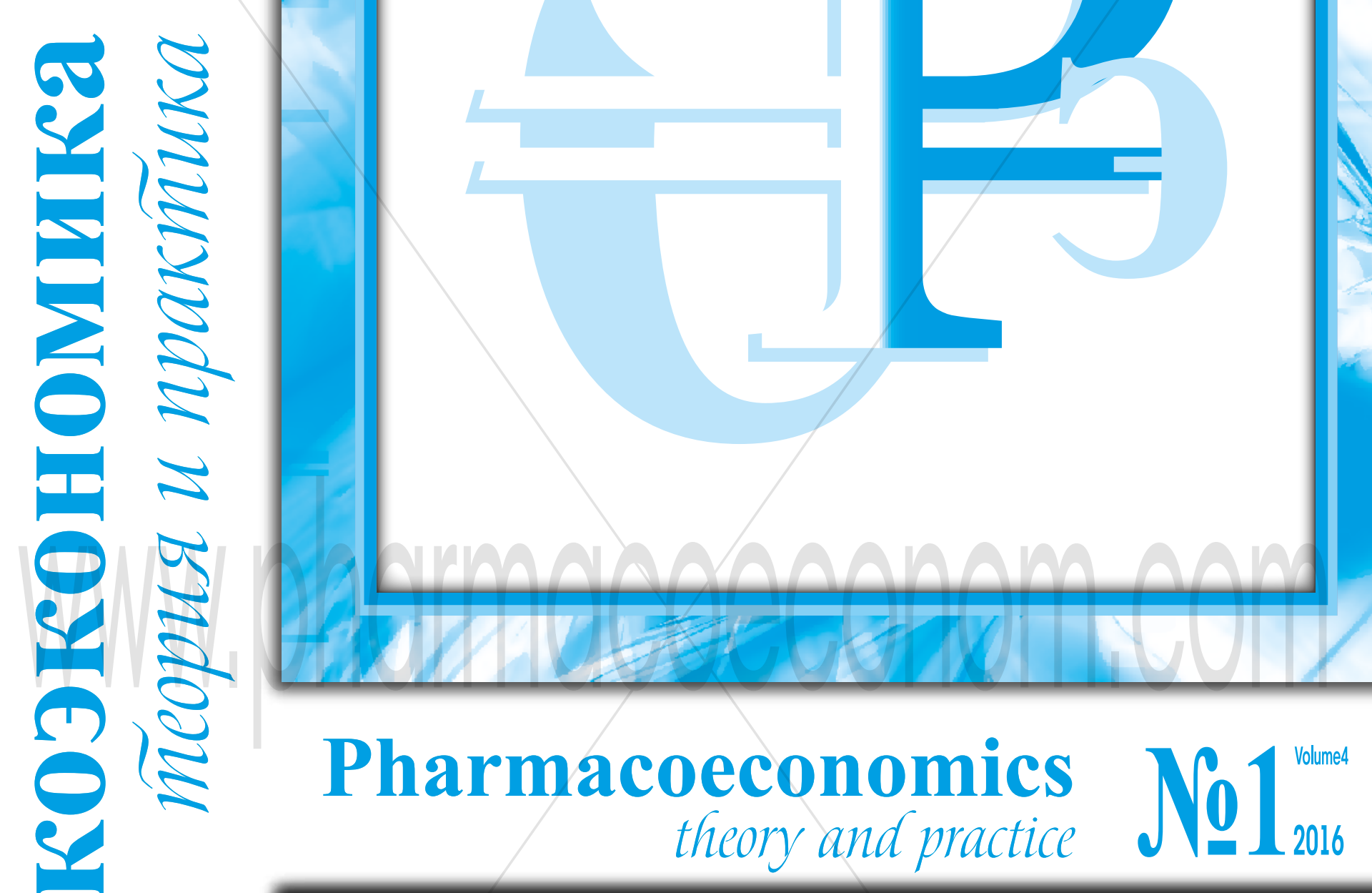

$\square$ МЕТОДОЛОГИЧЕСКИЕ ОСНОВЫ ФАРМАКОЭКОНОМИЧЕСКОГО МОДЕЛИРОВАНИЯ

$\square$ РЕЗУЛЬТАТЫ РОССИЙСКИХ ФАРМАКОЭКОНОМИЧЕСКИХ ИССЛЕДОВАНИЙ

口 МАТЕРИАЛЫ Х НАЦИОНАЛЬНОГО КОНГРЕССА С МЕЖДУНАРОДНЫМ УЧАСТИЕМ «РАЗВИТИЕ ФАРМАКОЭКОНОМИКИ И ФАРМАКОЭПИДЕМИОЛОГИИ В РОССИЙСКОЙ ФЕДЕРАЦИИ» 4-5 апреля 2016 г., г. Нижний Новгород 


\title{
PHARMACOECONOMIC ANALYSIS OF METFORMIN EXTENDED-RELEASE FORM USING IN DIABETES MELLITUS TYPE 2 TREATMENT
}

\author{
Novikov I.V., Kulikov A.Yu.
}

\section{I.M. Sechenov First Moscow State Medical University of the Ministry of Health of the Russian Federation}

Objective: to assess pharmacoeconomic aspects of treatment substitution of metformin immediate release (IR) form for metformin extended release (XR) form in diabetes mellitus (DM) type 2 treatment in Russian Federation healthcare system.

Methods: retrospective modelling performed according to standardized pharmacoeconomic methods such as: "cost-effectiveness analysis", "budget impact analysis", "sensitivity analysis". Markov model with 20-years time horizon was used to forecast compared therapy methods long-term impact on "cost-effectiveness" results in terms of QALY, direct and indirect costs. Analyzed competitors: Glucophage Long (metformin extended release (XR) form) and three generic metformin immediate release (IR) forms which are in the lead of consumption on Russian market (Siofor, Metformin-Richter, Formetin).

Results: the results of effectiveness analysis QALY-scores were 5.2925 and 4.6479 (20-years horizon with 3\% discount rate) for metformin XR and IR forms respectively. While total expenditures are 3169258.07 \& for Glucophage Long (XR form) therapy and 3422420.90 P, 3426951.18 ₹ and 3439108.79 \& for Formetin, Metformin-Richter and Siofor respectively.

Conclusion: metformin XR using improves glycemic control in comparison to metformin IR, which mediately (according to modelling results) decrease risk of DM complications and, in hence, decrease expenditures. Therefore and due to the most favorable tolerance, Glucophage Long therapy demonstrates the minimal total expenditures with the maximum QALY-scores.

Key words: diabetes mellitus (DM) type 2, QALY, CER, cost-effectiveness analysis, metformin, Glucophage Long.

\section{Introduction}

"Diabetes is worldwide increasing silent epidemy which can paralyze healthcare system in global scale" Robert Beaglehole citation, head of WHO chronical disease department. This epidemy becomes more and more actual in view of epidemiology data and forecasts.

In accordance to the new statistics every year 4.9 million people dying because of DM and these measurements are 3 times above earlier data. In 2000 number of patients with DM was at the rate of about 175 million people; however in 2014 this number increased to 387 million people. According to forecasts, the number of patients will be 592 million. According to WHO and IDF reports DM incidence is gaining generally in developing countries. Also according to the National Diabetes Patient Registry data, there were 3.96 million patients with diabetes registered in health facilities in 2014 and 3.2 million of them are DM type 2 patients. However the real number of patients is more than 6.7 million people according to epidemiology research. [4]

The risks of cardiovascular pathology, blindness, amputations and renal diseases are increasing as a result of inadequate DM control; at the same time the medical care of these episodes create the sufficient difficulties for healthcare system. According to Russian $\mathrm{MoH}$ data in 2014 near to $15 \%$ of healthcare budget allocated to control the diabetes disease. And $80 \%$ of these expenditures went for DM complications cure. If we don't take actions now, tomorrow expenditures will be considerably larger $[1,4,5]$. According to IDF data in 20141 DM type 2 patient's medical care took near to 1120 USD [2].

The development of treatment approach that could assure diabetes control and preclude or postpone complications is one of the most actual and complex issue of modern healthcare.

Antidiabetic therapy could be mono-component, double-component (with GPP-1 or DPP-4 inhibitors classes of drugs) and in case of noneffectiveness triple-component scheme used for patients with sufficient residual insulin level and pronounced insulin tolerance. The second and third components depends on the initial clinical situation could be incretin drugs (GPP-1 or DPP-4 inhibitors), sulphonylurea drugs/glinides and in some cases thiazolidinedione. The last stage is an insulin therapy in complex with oral antihyperglycemic drugs. However the benefits of insulin therapy are losing due to body-weight increasing, hypoglycemia episodes occurrence and/or losing of glycemic control.

Despite wide therapy opportunities, metformin is keeping the first line of antidiabetic therapy coupled with diet and physical activity, in case of no any contraindications. [25].

The effectiveness of the first line of antidiabetic therapy could be the most important for long-term effects, include economic effects associated with risk of complications and time that will be needed before insulin therapy started. There are a lot of metformin trade names and dosage forms and the optimizing of therapy and pharmacoeconomic analysis are required in this case. This publication is a result of pharmacoeconomic analysis of Glucophage Long (metformin XR) using instead of metformin IR for patients with DM type 2.

\section{Materials and methods \\ Competitors}

As the original one metformin XR Glucophage Long was used.

Based on IMS pharmaceutical market monitoring data three competitors were chosen due to monocomponent active substance "metformin" and the largest market share in 2015. As the result the compared alternatives were:

Glucophage Long

Siofor 
Formetin

Metformin-Richter

\section{The model structure description}

There were standard pharmacoeconomic methods used in this retrospective study: "cost-effectiveness", "budget impact" and "sensitivity analysis".

Model horizon was 20 years and discount rate was $3 \%$ per year. The probabilistic Markov model has been developed on the base of Microsoft Excel software which allowed forecasting therapy's impact in long-term period.

The duration of each cycle in Markov model was 1 year period. To reach primary endpoints of compared therapies' efficacy randomized clinical trials (RCT) data was used. There were efficacy of compared therapy alternatives have been expressed through the level of glycohemoglobin $\left(\mathrm{HbA}_{1 \mathrm{c}}\right)$ decreasing, patients' treatment adherence and tolerability expressed in frequencies of adverse effects. Secondary efficacy endpoints were presented through rates of macro- and microvascular complications related to DM type 2. These predicted rates were modeled on the basis of RCT data about $\mathrm{HbA}_{1 \mathrm{C}}$ level changes and UKPDS data about impacts of these levels changes on complications risk rates. The terminal endpoint in pharmacoeconomic research was an integral measure of effectiveness (utility) QALY, which is representing the number of additional quality life years in 20-years horizon and is taking into account the impact of complications, adverse effects frequencies and body-weight changes.

\section{Effectiveness analysis}

There were clinical trials comparing metformin $X R$ and $I R$ influence on adherence, $\mathrm{HbA}_{1 \mathrm{c}}$ decreasing ability, on body-mass index (BMI) effects and on adverse reactions frequencies.

Antidiabetic therapy adherence and level glycaemic control data were examined in retrospective study performed by L.A. Donnelly, A. D. Morris \& E. R. Pearson «Adherence in patients transferred from immediate release metformin to a sustained release formulation: a population-based study» on 10909 patient cohort (13-years horizon data). In metformin XR cohort, 137 patients, adherence-level was higher $(80 \%)$ than in metformin IR group (72\%) (10772 patients). 40 patients whose adherence-data was enough for examination changed metformin IR therapy to metformin XR therapy. The adherence-level in these patients increased from $62 \%$ to $81 \%$; and mean HbA1c-value went down from $9,1 \%$ to $8,4 \%$ respectively (data of 29 patients). The average daily dose of metformin XR was $1374 \mathrm{mg}$ and the average dose of metformin IR was $1581 \mathrm{mg}$. Therefore, this clinical trial demonstrated that metformin XR provide higher adherence level and, consequently, improve glycemic level control with smaller average daily dose than metformin IR. The results used in effectiveness analysis and demonstrated in Table 1. [7]

In cohort study performed by Blonde L, Dailey GE, Jabbour S. et al. "Gastrointestinal tolerability of extended-release metformin tablets compared to immediate-release metformin tablets: results of a retrospective cohort study» ( $n=471$, duration: 52 weeks) 310 patients' medical cards were analyzed who were taken metformin XR and 158 patients' cards with metformin IR antidiabetic therapy. Both groups included patients with first line antidiabetic therapy, which started not earlier than 2 years before. Also patients with adverse effects were included in study with the exception of patients who had sufficient disease of gastrointestinal tract, renal and hepatic decompensation on moderate and hard stage. Primary and secondary endpoints were overall gastrointestinal intolerability and diarrhea rates per year. 205 patients whose cards were included in study changed therapy from metformin IR to metformin XR. Overall frequency of gastrointestinal adverse effects was $26.34 \%$ for metformin IR cohort and $11.71 \%$ for XR cohort. Diarrhea frequency fell down from $18.05 \%$ to $8.29 \%$ with underlying on changing form of release to XR. There is no statistically significant differences in average daily dose in metformin XR and metformin IR groups. The results of this study presented in Table 2. [8]

Table 1. The results of analysis of the primary efficacy end-points. [7]

\begin{tabular}{|c|c|c|c|c|}
\hline Therapy & HbA1c (\%) & BMI & $\begin{array}{c}\text { Daily dose } \\
(\mathrm{mg})\end{array}$ & Adherence (\%) \\
\hline Metformin XR & 8,40 & 31,90 & 1374 & $81 \%$ \\
\hline Metformin IR & 9,10 & 32,20 & 1581 & $62,3 \%$ \\
\hline
\end{tabular}

Table 2. Therapy tolerability data. [8]

\begin{tabular}{|c|c|c|c|c|c|}
\hline Therapy & Diarrhea & Nausea & Dyspepsia & $\begin{array}{c}\text { Abdominal } \\
\text { distention }\end{array}$ & Tympanism \\
\hline $\begin{array}{c}\text { Metformin } \\
\text { XR }\end{array}$ & $8,29 \%$ & $1,95 \%$ & $1,46 \%$ & $0,49 \%$ & $0,00 \%$ \\
\hline $\begin{array}{c}\text { Metformin } \\
\text { IR }\end{array}$ & $18,05 \%$ & $2,93 \%$ & $3,41 \%$ & $2,44 \%$ & $2,44 \%$ \\
\hline
\end{tabular}

\section{Impact on complications}

UKPDS (The United Kingdom Prospective Diabetes Study) data used to assess the study endpoints impact on complication risks in effectiveness analysis. In "Association of glycaemia with macrovascular and microvascular complications of type 2 diabetes (UKPDS 35): prospective observational study" study (average duration: 10 years) 4585 patients were involved in assessment of risks reducing associated with decreasing of average HbA1cvalue with potential interfering factors at diagnosing moment taken in to account. Primary endpoints were "death related to DM rate" and "all-cause mortality rate". The secondary endpoints were risks of myocardial infarction, stroke, amputation (including death from peripheral vascular disease), and microvascular disease (predominantly retinal photo-coagulation), non-fatal heart failure and cataract extraction.

The UKPDS results and mean risk rates for base case of patients characteristics used in effectiveness analysis are presented in Table 3.

Table 3. DM type 2 complications rates.

\begin{tabular}{|c|c|c|}
\hline Event: & UKPDS 35 & UKPDS 35 \\
\hline Death related to DM & $\begin{array}{c}\text { Decreasing risk rate per } \\
\text { decreasing } \mathrm{HbA}_{10} \text {-value } \\
\text { on 1\% }\end{array}$ & $\begin{array}{c}\text { Events per 1000 } \\
\text { patient-years* }\end{array}$ \\
\hline All-cause mortality & $21 \%$ & 23.5 \\
\hline Stroke & $14 \%$ & 8.3 \\
\hline Myocardial infarction & $12 \%$ & 7.4 \\
\hline Heart failure & $14 \%$ & 30 \\
\hline Amputation & $16 \%$ & 4.4 \\
\hline $\begin{array}{c}\text { Microvascular complica- } \\
\text { tions }\end{array}$ & $43 \%$ & 4 \\
\hline Cataract & $37 \%$ & 22.8 \\
\hline
\end{tabular}

* - in case of average $\mathrm{HbA}_{1 \mathrm{c}}$ level equals $8.0 \%$, mean age: 54 , mean monitoring duration: 10 years.

Apart from UKPDS data in this pharmacoeconomic study used risk rates associated with $1 \% \mathrm{HbA}_{1 \mathrm{c}}$ decreasing presented in publication Khaw $\mathrm{KT}$ et al $(n=10232)$ : coronary artery disease (CAD) decrease rate: $23 \%$; and angina decrease rate: $14 \%$. There was assumption that average incidence of CAD and angina for base cohort $\left(\mathrm{HbA}_{1 \mathrm{c}}=8.0 \%\right.$, average age: 54$)$ were equal 30 events per 1000 patient-years, such as heart attack incidence.

\section{QALY-evaluation}

In cost-effectiveness analysis QALY measurement used. There were utility indices for each state of health in each estimated part of period used in overall QALY calculation for time horizon. Differences in utility indices depend on DM complications, body mass index (BMI) and adverse effects rates.

Utility scores have been calculated per each year for the purpose of quality of life evaluation for DM type 2 patients and assessment of complications and BMI impact on it. The base value of QALY per year for patients without sufficient micro- and macrovascular diseases was 0.82 in accordance to study «Using the EQ-5D index score as a predictor of outcomes in patients with type 2 diabetes» $(n=738)$ [17]. Complications or hypoglycemic states, changes in BMI or mortality all of these events affected on QALY. QALY-scores went 
down to "0" point in case of death from the moment of death to the finish of modeling. Complications entailed an intensive loss of QALY in the year of event emergence and equal (or less) rejection of scores in each year till the finish of model time horizon (Table 4).

There is QALY-scores calculation for patient with heart attack on the $2^{\text {nd }}$ year of therapy in 5 years time horizon analysis, for instance. At the $1^{\text {st }}$ year of therapy QALY-score for this patient was equal base mean for such scores for DM type 2 patients: 0.82 . At the $2^{\text {nd }}$ year QALY-scores decreased in cause of heart attack on 0,055 and equaled 0,765 . Every next year in this analysis QALY-scores were decreased on 0,0012 in comparison to the base level $(0,82)$, and was equal 0,808 QALY for this patient. In such a way in 5-years period QALY for this patient was equal: $0,82+0,765+0,808 * 3=4,009$ QALY.

Table 4. Impact of complications on values of utility in model.

\begin{tabular}{|c|c|}
\hline Event/state & Impact on QALY (utility decreasing) \\
\hline Stroke & $-0,164^{\mathrm{a}}$ \\
\hline Stroke (next years) & $-0,04^{\mathrm{b}}$ \\
\hline Myocardial infarction & $-0,055^{\mathrm{a}}$ \\
\hline Myocardial infarction (next & $-0,012^{\mathrm{c}}$ \\
\hline years) & $0,041^{\mathrm{b}}$ \\
\hline Angina & $-0,024^{\mathrm{b}}$ \\
\hline Angina (next years) & $-0,108^{\mathrm{a}}$ \\
\hline Heart failure & $-0,018^{\mathrm{c}}$ \\
\hline Heart failure (next years) & $-0,09^{\mathrm{a}}$ \\
\hline Coronary artery disease & $-0,28^{\mathrm{a}}$ \\
\hline Amputation & $-0,0252^{\mathrm{d}}$ \\
\hline $\begin{array}{c}\text { Microvascular } \\
\text { complications }\end{array}$ & $-0,017^{\mathrm{b}}$ \\
\hline Cataract & $-0,074^{\mathrm{a}}$ \\
\hline Blindness(one-side) & $-0,0271^{\mathrm{e}}$ \\
\hline Gastrointestinal adverse & $-0,0061^{\mathrm{f}}$ \\
\hline effects & \\
\hline BMI Increasing on 1 point & \\
\hline
\end{tabular}

a - According to «Estimating utility values for health states of type 2 diabetic patients using the EQ-5D (UKPDS 62)» [18];

b - According to "Cost-effectiveness of insulin analogues for diabetes mellitus» [19] c - According to "Methods for the economic evaluation of health care programs» [21] $d$ - Used an average rate of utility-decreasing in case of renal failure $(-0,0263)$ from publication «A model to estimate the lifetime health outcomes of patients with type 2 diabetes: UKPDS Outcomes Model (UKPDS 68)" data and in case of neuropathy $(-0,024)$ from pharmacoeconomic study «Cost-effectiveness of insulin analogues for diabetes mellitus» [22];

e - According to R. A. Elliott et.al. [16], 10-days utility-impact data.

f - Utility-vales for patients with BMl>25 from study «Modelling EuroQol health-related utility values for diabetic complications from CODE-2 data» [23].

\section{Cost analysis}

Cost analysis is represented as direct costs calculation including antidiabetic therapy and medical procedures in accordance to national guidelines of medical care for DM type 2 and indirect costs (expenditures associated with DM complications).

Used dosage scheme corresponds to studies, which results applied in effectiveness analysis (metformin XR $1374 \mathrm{mg}$ daily, metformin IR $1581 \mathrm{mg}$ daily). The calculation of pharmacotherapy costs based on prices in register of Essential Drug List. The results of calculation demonstrated in Table 5.

Prices of medical procedures used from Schedule of Rates of Moscow State Compulsory Health Insurance Fund (as at 2015) [11]. Calculations of expenditures for DM complications based on national publications (Dedov I.I., 2010, table 6). [12]
Table 5. Results of calculation of average costs of pharmacotherapy for 1 patient per year.

\begin{tabular}{|c|c|c|}
\hline $\begin{array}{l}\text { Costs of } \\
\text { pharmacotherapy }\end{array}$ & Costs per day & Costs per year \\
\hline Glucophage Long & $13,75 \mathrm{P}$ & 5017,72 P \\
\hline Formetin & $5,01 ₹$ & $1830,09 ?$ \\
\hline Metformin-Richter & 6,12 ? & $2234,14 \mathrm{P}$ \\
\hline Siofor & $9,09 ?$ & $3318,45 \mathrm{P}$ \\
\hline
\end{tabular}

Table 6. Expenditures for DM complications

\begin{tabular}{|c|c|c|}
\hline \multirow{2}{*}{$\begin{array}{c}\text { State of health/Adverse } \\
\text { event }\end{array}$} & \multicolumn{2}{|c|}{ Expenditures, RUB } \\
\cline { 2 - 3 } Stroke & First year & Every next year \\
\cline { 2 - 3 } & 307446 & 23532 \\
\hline Myocardial infarction & 417027 & 259575 \\
\hline Blindness & 48404 & - \\
\hline Angina & 260552 & 259575 \\
\hline Heart failure & 27946 & 27840 \\
\hline Amputation & 450996 & - \\
\hline Cataract & 27000 & - \\
\hline $\begin{array}{c}\text { Other microvaseular } \\
\text { complications (neuropathy, } \\
\text { nephropathy) }\end{array}$ & 522789 & 55610 \\
\hline
\end{tabular}

\section{Cost-effectiveness analysis}

At the last stage of costs analysis the overall costs have been calculated per 1 patient for 20 years period (time horizon). Direct costs represented such as sum of pharmacotherapy costs and medical procedures and medical services expenditures. Indirect costs represented as expenditures for DM type 2 complications.

Intermediary output was evaluation of release form change impact on DM complications rates (Table 7).

Table 7. Evaluation of release form changes for 10000 patients. Impact on number of complications per 20 years.

\begin{tabular}{|c|c|}
\hline Events & $\begin{array}{c}\text { Additionally prevented events: substitution of IR for } \\
\text { XR }\end{array}$ \\
\hline Stroke & 124 \\
\hline Myocardial infarction & 588 \\
\hline Blindness & 591 \\
\hline Angina & 588 \\
\hline CAD & 966 \\
\hline Heart failure & 99 \\
\hline Amputation & 241 \\
\hline $\begin{array}{c}\text { Microvascular } \\
\text { complications }\end{array}$ & 1181 \\
\hline Cataract & 184 \\
\hline Death related to DM & 691 \\
\hline All-cause mortality & 163 \\
\hline
\end{tabular}

Calculated number of complications was translated in QALY-scores for utility evaluation. Cost-effectiveness ratio calculated by formula:

$$
\text { CER }=\text { Cost/QALY, }
$$

CER - cost-effectiveness ratio

Costs - overall costs for current therapy alternative, RUB;

QALY - incremental value of effectiveness, which indicate quality adjusted life years 
Table 8. Cost-effectiveness results per 1 patient. Time horizon 20 years, discount rate $3 \%$.

\begin{tabular}{|c|c|c|c|c|}
\hline $\begin{array}{c}\text { Costs/Therapy } \\
\text { alternatives }\end{array}$ & $\begin{array}{c}\text { Glucophage } \\
\text { Long }\end{array}$ & Formetin & $\begin{array}{c}\text { Metformin- } \\
\text { Richter }\end{array}$ & Siofor \\
\hline $\begin{array}{c}\text { Total direct costs, } \\
\text { RUB }\end{array}$ & 899633 & 863893 & 868423 & 880580 \\
\hline $\begin{array}{c}\text { Total indirect } \\
\text { costs, RUB }\end{array}$ & 2269624 & 2558527 & 2558527 & 2558527 \\
\hline Overall costs, RUB & 3169258 & 3422420 & 3426951 & 3439108 \\
\hline QALY & 5,2925 & 4,6479 & 4,6479 & 4,6479 \\
\hline CER & 598820 & 736335 & 737310 & 739926 \\
\hline
\end{tabular}

Finally, Glucophage Long antidiabetic therapy demonstrates the higher utility value (in QALY measurements) with the smaller overall costs in comparison to alternative therapies with metformin IR. Such a results of Pharmacoeconomic analysis interpret Glucophage Long as "dominant" method of antidiabetic monotherapy for DM type 2 patients.

\section{Budget impact analysis}

The implementation of budget impact analysis provides an opportunity to financial assessment of health technologies penetration in market. That opportunity is very important for decision-making process in healthcare field. This type of analysis implicate a comparative approach: the result of "budget impact" equals to distinction between cumulative economic impact (loss or benefit) of analyzing healthcare technologies.

The result calculated by formula:

$$
\mathrm{BIA}=\mathrm{S}(1)-\mathrm{S}(2)
$$

$B I A$ - result of "budget impact" analysis in terms of money (cost saving or additional expenditures)

$S(1), S(2)$ - cumulative expenditures for using combinations of different antidiabetic therapies.
The economic impact for 100 patients in tentative cohort per 20 years in case of switching the metformin release form (IR to XR - Glucophage Long, table 9). Only financial component was assessed, including costs of pharmacotherapy, medical services (according to national guidelines) and expenditures for DM type 2 complications. In such a manner, calculated costs represent direct expenditures of healthcare budget explicitly.

Table 9. Market shares of drugs settings. Values are corresponding to IMS data in 2015 .

\begin{tabular}{|c|c|c|}
\hline Therapy & $\begin{array}{c}\text { Settings for current year } \\
\text { (\% of patients) }\end{array}$ & $\begin{array}{c}\text { Settings for forecast } \\
\text { (\% of patients) }\end{array}$ \\
\hline Glucophage Long & 6 & 100 \\
\hline Formetin & 29 & 0 \\
\hline Metformin-Richter & 17 & 0 \\
\hline Siofor & 48 & 0 \\
\hline
\end{tabular}

Overall budget with respect to market share settings are $341601146 \mathrm{P}$ for current year and 316925807 P in forecast. Similarly calculated pharmacotherapy costs are $3144418 \mathrm{P}$ and $5625994 \mathrm{P}$ in current and forecast years respectively.

It was revealed in the result of budget impact that increasing of Glucophage Long market share in antidiabetic monotherapy lead to $24675339 \mathrm{P}$ budget saving per 20 years (1 233770 \& - average account per year) per 100 patients group. The results of budget impact analysis in terms of pharmacotherapy expenditures and overall expenditures are presented in 1 and 2 figures respectively.

\section{Sensitivity analysis}

Sensitivity analysis have been done to assess reliability of pharmacoeconomic results. Against to background of research practice in Russia, price characteristics were not varying in this model. This condition based on low proportion of drugs costs in overall expenditures also a probability of drug prices varying is not sufficient in cause of price regulatory policies in Russian Federation. Double factor sensitivity analysis have been done in as fullest

\section{Pharmacotherapy costs in BIA, RUB}

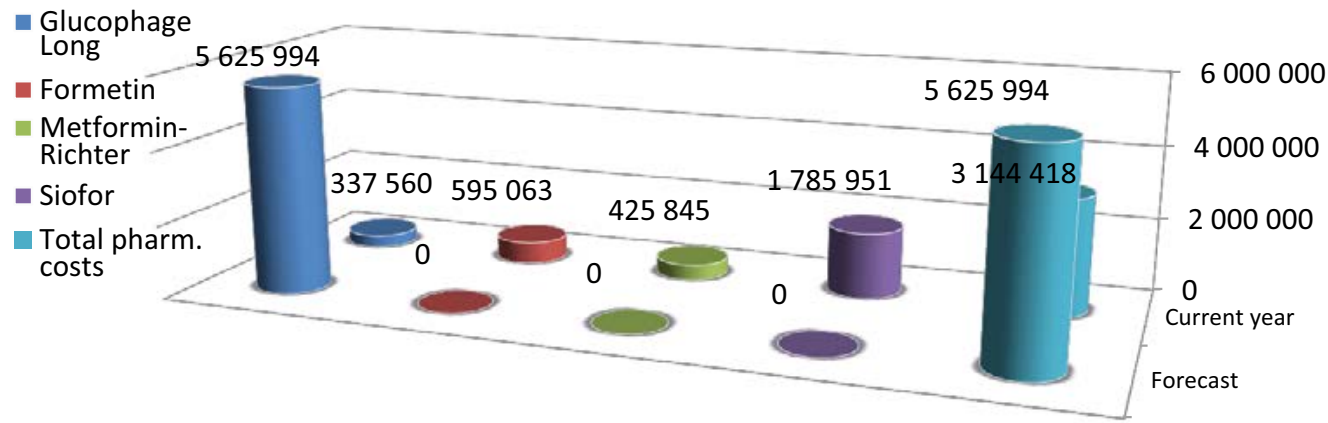

Figure 1. The impact of market share on drug expenditures

\section{Overall costs per therapy subgroups in $B I A, R U B$}

Figure 2. The overall results of budget impact analysis depending on market share

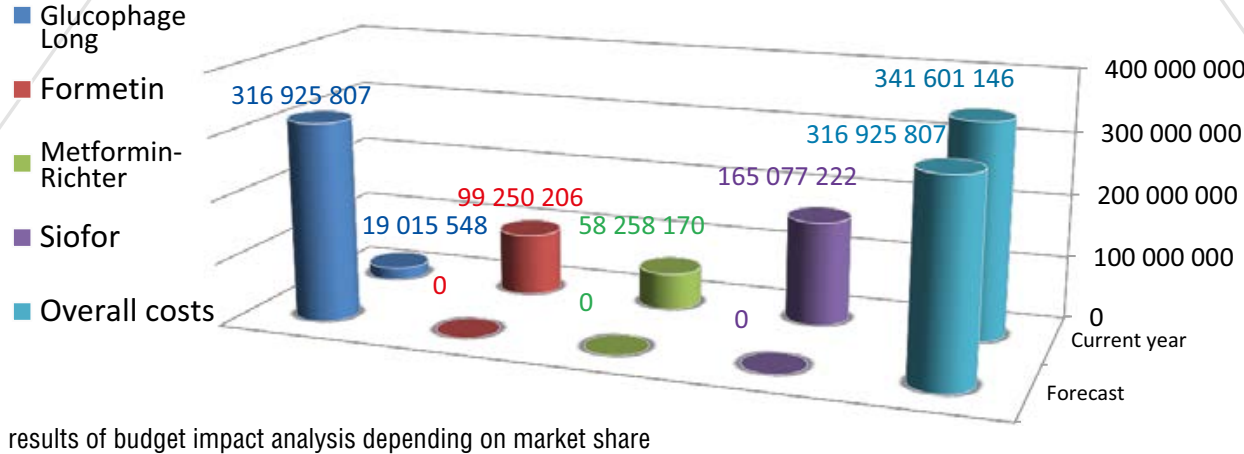


version as it possible within the context of pharmacoeconomic research.

The first varying factor was dosage of drugs. In that case of sensitivity analysis it was assumed that required daily doses of XR and IR metformin are equal to $1500 \mathrm{mg}$ per day.

The second factor in sensitivity analysis was efficacy data for therapy alternatives. In Donelly study [7] results of $\mathrm{HbA} 1 \mathrm{c} \%$ level could be considered as non-conclusive in view of small cohort of patients. For this reason the sensitivity analysis based on verified distinction between adherence rates of the alternative release forms and it have taken to consideration as "the worst case" - meaning that the smallest impact of adherence rates found during literature review have been used.

There are 3 publications of correlation between therapy adherence and level of $\mathrm{HbA}_{1 \mathrm{c}} \%$. One of this publication in which impact of therapy adherence on $\mathrm{HbA}_{1 \mathrm{c}} \%$ level was the smallest (decreasing of adherence on $1 \%$ giving only $0,01 \%$ variation of $\mathrm{HbA} 1 \mathrm{c} \%$ level), provides the basis of sensitivity analysis. The results of analysis presented in table 10 .

Double-factor sensitivity analysis says that cost-effectiveness analysis results are sustainable to varying of effectiveness data of alternative therapies. Overall costs of Glucophage Long therapy was lower in comparison with alternative therapies. Calculations in this case based on the assumption that daily doses of comparators (XR and IR metformin) are equal (table 10). The sustainability of results in this "sensitivity case" means that results of model are reliable.

Table 10. The results of cost-effectiveness in sensitivity analysis - "the worst case".

\begin{tabular}{|c|c|c|c|c|}
\hline $\begin{array}{l}\text { Therapy } \\
\text { alternatives }\end{array}$ & $\begin{array}{l}\text { Glucophage } \\
\text { Long }\end{array}$ & Formetin & $\begin{array}{l}\text { Metformin- } \\
\text { Richter }\end{array}$ & Siofor \\
\hline Total direct costs & 904792 P & 862841 P & 867139 P & 878674 P \\
\hline $\begin{array}{l}\text { Total indirect } \\
\text { costs }\end{array}$ & 2142447 P & 2209297 P & 2209297 P & 2209297 f \\
\hline Overall costs & $3047239 \mathrm{f}$ & $3072139 \mathrm{P}$ & $3076437 \mathrm{P}$ & $3087972 \mathrm{P}$ \\
\hline QALY & 5,2925 & 5,1033 & 5,1033 & 5,1033 \\
\hline
\end{tabular}

\section{Results of Pharmacoeconomic research}

This research assess result of changing of antidiabetic therapy - from IR to XR (Glucophage Long) in terms of effectiveness and safety of therapy, expenditures for DM type 2, costs of complications and quality of patients life.

Effectiveness analysis says that Glucophage Long therapy arrange the best control of glycose profile that has an impact on DM complications frequencies (lowering). Also Glucophage Long therapy demonstrates a lower rates of gastrointestinal adverse effects in comparison with IR metformin. These factors indirectly, in association with impact of the best BMI control effects, have been represented as QALY-scores, which estimated as 5.2925 QALY for Glucophage Long therapy and 4.6479 QALY for IR metformin therapy.

Overall costs for DM type 2 therapy and expenditures for complications were estimated in course of cost analysis. The results demonstrate economy of overall budget in case of Glucophage Long therapy. That economy covers additional expenditures for pharmacotherapy subgroup of expenditures. The economy of overall costs becomes possible in cause of reducing macro- and microvascular complications and expenditures for it.

Glucophage Long is a "dominant" method of first line antidiabetic monotherapy in comparison to Formetin, Metformin-Richter and Siofor because it lead to a higher efficacy with a lower costs. Sensitivity analysis says that results of cost-effectiveness analysis are reliable and in "the worst case" Glucophage Long therapy demonstrates higher level of QALY with lower costs.

\section{References}

1. Sountsov Yu. I., Dedov I. I.: The State Register of Diabetec Patients - the main information system calculating and planning the state economic spending on Diabetes. Sakharny Diabet N2, 2005

2. IDF Diabetes Atlas 6th edition, 2014 update @ International Diabetes Federation, 2014
3. Inzucchi SE, Bergenstal RM, Buse JB. Management of Hyperglycemia in Type 2 Diabetes: A Patient-Centered Approach. Position Statement of the American Diabetes Association (ADA) and the European Association for the Study of Diabetes (EASD). Diabetes Care 2012;35:1364-1379

4. Al Dedov, MV Shestakova. Algorithms of specialized medical care for patients with diabetes. 7 th edition. Sakharny diabet 2015;18(1S):1-112

5. Rodbard H. W., the AACE Diabetes Mellitus Clinical Practice Guidelines Task Force. American Association of Clinical Endocrinologists medical guidelines for clinical practice for the management of diabetes mellitus. Endocrine Pract. 2007;13(suppl 1):3-68

6. Guillausseau PJ. Influence of oral antidiabetic drugs compliance on metabolic control in type 2 diabetes. A survey in general practice. Diabetes Metab 2003;29(1):79-81

7. Donnelly LA, Morris AD, Pearson ER. Adherence in patients transferred from immediate release metformin to a sustained release formulation: a population-based study. Diabetes Obes Metab. 2009 Apr;11(4):338-42

8. Blonde L, Dailey GE, Jabbour S. Gastrointestinal tolerability of extended-release metformin tablets compared to immediate-release metformin tablets: results of a retrospective cohort study. Curr Med Res Opin. 2004 Apr;20(4):565-72.

9. Rozenfeld Y, Hunt JS, Plauschinat C, Wong KS. Oral antidiabetic medication adherence and glycemic control in managed care. Am J Manag Care. 2008 Feb;14(2):71-5.

10. Mary K. Rhee, Wrenn Slocum, David C. Ziemer. Patient Adherence Improves Glycemic Control. The Diabetes Educator March/April 2005 vol. 31 no. 2 240-250

11. http://ora.ffoms.ru/

12. Dedov II, Shestakova MI, Suntsov Yul, Yagudina RI, Krysanov IS, Kulikov AYu, Arinina EE. Pharmacoeconomic simulation of delayed results of the treatment of type 2 diabetes mellitus with modern insulin analogs in comparison with oral hypoglycemic agents. Diabetes Mellitus. 2010;(1):102110. Russian.

13. Stratton IM, Adler Al, Neil HA, Matthews DR, Manley SE, Cull CA, Hadden D, Turner RC, Holman RR: Association of glycemia with macrovascular and microvascular complications of type 2 diabetes (UKPDS 35): prospective observational study. BMJ 321:405-412, 2000

14. Turner RC, Cull CA, Frighi V, Holman RR, UK Prospective Diabetes Study (UKPDS) Group: Glycemic control with diet, sulfonylurea, metformin, or insulin in patients with type 2 diabetes mellitus: progressive requirement for multiple therapies (UKPDS 49). JAMA 281:2005-2012, 1999

15. Khaw KT, Wareham N, Bingham S, et al. Association of hemoglobin A1c with cardiovascular disease and mortality in adults: the European Prospective Investigation into Cancer in Norfolk. Ann Intern Med 2004;141:413-20.

16. R. A. Elliott, L. Hooper, K. Payne. Preventing non-steroidal anti-inflammatory drug-induced gastrointestinal toxicity: are older strategies more cost-effective in the general population? Rheumatology 2006;45:606-613

17. Clarke PM, Hayes AJ, Glasziou PG. Using the EQ-5D index score as a predictor of outcomes in patients with type 2 diabetes. Med Care. 2009 Jan;47(1):61-8.

18. Clarke $P$, Gray A, Holman R. Estimating utility values for health states of type 2 diabetic patients using the EQ-5D (UKPDS 62). Med Decis Making. 2002 Jul-Aug;22(4)

19. Chris G. Cameron MSc, Heather A. Bennett BPharm PhD. Cost-effectiveness of insulin analogues for diabetes mellitus CMAJ February 17, 2009 vol. 180,4

20. Patrick W. Sullivan, PhD and Vahram Ghushchyan, PhD. Preference-Based EQ-5D Index Scores for Chronic Conditions in the United States. Med Decis Making. 2006; 26(4): 410-420.

21. Drummond MF, Sculpher MJ, Torrance GW, et al. Methods for the economic evaluation of health care programs. 3rd ed. Oxford (UK): Oxford University Press; 2005.

22. Clarke PM, Gray AM, Briggs A, Farmer AJ A model to estimate the lifetime health outcomes of patients with type 2 diabetes: the United Kingdom Prospective Diabetes Study (UKPDS) Outcomes Model (UKPDS no. 68). Diabetologia. 2004 0ct;47(10):1747-59

23. Bagust $A$, Beale $S$. Modelling EuroQol health-related utility values for diabeti ccomplications from CODE-2 data. Health Econ 2005 Mar; 14 (3):217-30.

24. MoH RF Percept "Standard of medical care of patients with diabetes mellitus" 18 Jan 2013]

25. DeFronzo RA: Pathogenesis of type 2 diabetes: implications for met- 
formin. Drugs 58, 29-30, 1999

26. [Yagudina R.I., Kulikov A.Yu., Novikov I.V., The modern methodology of sensitivity analysis in pharmacoeconmics research//Pharmacoeconomics: pharmacoeconomics and pharmacoepidemiology, 2010; N4: C.8-12

27. 27.Methodology basics of Pharmacoeconomic analysis/ R.U. Khabriev, A.Yu. Kulikov, E.E. Arinina M. 2011 